\title{
Hybrid bypass technique to mitigate leakage current in the grid-tied inverter
}

\author{
Geetha Kamurthy, Sreenivasappa Bhupasandra Veeranna \\ Center for Research in Power Electronics, Department of Electronics and Communication Engineering, Presidency University, \\ Bangalore, India
}

\begin{tabular}{l} 
Article Info \\
\hline Article history: \\
Received Jan 4, 202 \\
Revised Jul 16, 202 \\
Accepted Aug 4, 2021 \\
\hline Keywords: \\
Grid-tied inverter \\
Leakage current \\
Single-phase \\
Transformerless
\end{tabular}

Transformerles

\begin{abstract}
The extensive use of fossil fuel is destroying the balance of nature that could lead to many problems in the forthcoming era. Renewable energy resources are a ray of hope to avoid possible destruction. Smart grid and distributed power generation systems are now mainly built with the help of renewable energy resources. The integration of renewable energy production system with the smart grid and distributed power generation is facing many challenges that include addressing the issue of isolation and power quality. This paper presents a new approach to address the aforementioned issues by proposing a hybrid bypass technique concept to improve the overall performance of the grid-tied inverter in solar power generation. The topology with the proposed technique is presented using traditional $\mathrm{H} 5, \mathrm{oH} 5$ and $\mathrm{H} 6$ inverter. Comparison of topologies with literature is carried out to check the feasibility of the method proposed. It is found that the leakage current of all the proposed inverters is $9 \mathrm{~mA}$ and total harmonic distortion is almost about $2 \%$. The proposed topology has good efficiency, common mode and differential mode characteristics.
\end{abstract}

This is an open access article under the CC BY-SA license.

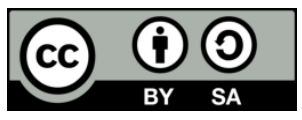

\section{Corresponding Author:}

Geetha Kamurthy

Center for Research in Power Electronics

Department of Electronics and Communication Engineering, Presidency University

Bangalore-560064, Karnataka, India

Email: geetha.mallik@gmail.com

\section{INTRODUCTION}

According to long-term national strategies traditional power generation resources are unsustainable. Moreover, the electricity generation system is primarily reliant on fossil fuel combustion. Because those resources are nonrenewable and are considered the principal cause of contamination, substantial research is being performed to develop new alternative energy sources and upgrade renewable energy sources. Renewable energy resources have been widely installed for grid interconnection in the recent decade [1]-[3]. In contrary to the remaining renewable energy sources, wind and photovoltaic (PV) are usually used as a backup system to the major production resources [4]. A solar PV system is one of the most common solarpowered renewable energy source. Photovoltaic panels rely on the sun's radiation to generate electricity. There is enough sunlight during the day to keep the cells operating at maximum efficiency. However, energy production drops dramatically in the evening. Although most power is being used during the day, it is also needed at night. The energy utilisation counter can be inverted unless the photovoltaic panels are connected to the power grid, forcing the need to store power generated during the day so that it can be used overnight or on heavy rainy nights [5]. Despite these solar PV installation has exploded in recent years, and in some countries, it now plays a critical role in electricity generation. Figure 1 shows power generation using renewable energy resources worldwide over the last decade [6]. Figure 2 shows solar capacity in the top five 
countries in 2020 [7]. It can be observed that the cumulative generation of power using solar energy is rapidly increasing compared to other renewable energies. Hence, integrating the solar power systems in distributed power generation system plays an important role and hence the power converters required.

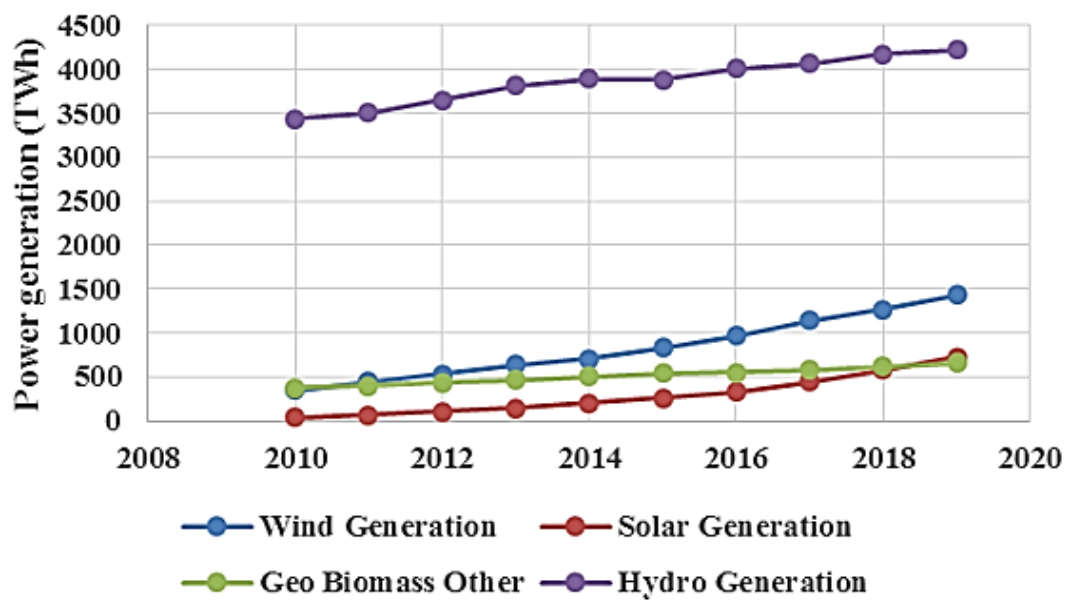

Figure 1. Renewable energy consumption world wide

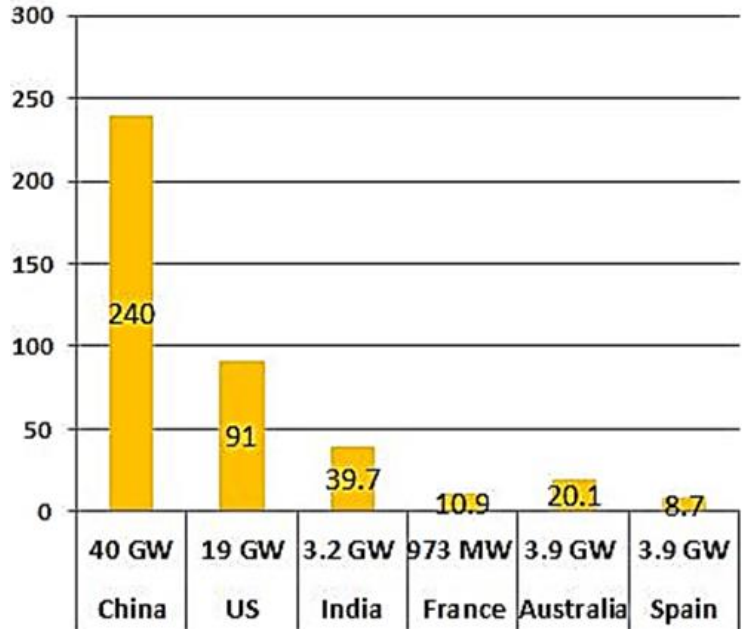

a Cumulative Capacity...

Figure 2. Cumulative solar capacity $(\mathrm{GW})[7]$

The grid-tied inverter has a DC-DC converter, inverter and control system. The DC-DC converter are used to boost the power received from the PV panel to the required level and to give stable output. It requires a control algorithm to control the power switches used. The inverter receives a DC from the boost converter and converts it into AC power that can be either used to run exiting loads or can be fed into the grid to form a grid-connected inverter. The two functions that a grid-connected PV inverter system must fulfil are the ability to track the maximum power point (MPPT) to collect the maximum power from solar PV and the capacity to realise a voltage and current control technique for smooth power flow to the load and grid [8], [9]. As a result, the grid-tied inverter system keeps the DC link voltage constant and regulates the flow of active and reactive power to the grid [10], [11]. Grid-connected PV systems range in size from a few hundred watts to hundreds of megawatts. A stray or parasitic capacitance exists between the photovoltaic cell and earth ground. Hence a leakage current flows between the grid and the photovoltaic cell when photovoltaic cells are used to generate power in a distributed power generation system. As a result, isolation between the grid and the photovoltaic cell must be provided to prevent the flow of this leakage current, which causes electromagnetic interference and is also dangerous [12]. The stray capacitance varies up to $150 \mathrm{nF} / \mathrm{kW}$ depending on the atmospheric conditions [13]. To prevent leakage current, a low-frequency transformer is 
used as an isolator. The line transformer makes the inverter bulkier, heavier, and more expensive. As a result, in a grid-tied inverter, the line transformer is removed. This transformerless grid-tied inverter offers lower cost, lighter weight, smaller volume, higher efficiency and less complexity compared to transformer-based inverters. To reduce the leakage current, the removed transformer must be compensated with a suitable galvanic isolation technique. Figure 3(a) show a conventional full-bridge inverter with four switches. When used in transformerless grid-tied inverter it is necessary to provide isolation to avoid the problems related to leakage current. The topologies built with galvanic isolation technique are primarily divided into two categories based on leakage current reduction approaches. They are galvanic isolation with common-mode voltage clamping and galvanic isolation without common-mode voltage clamping.

Grid-tied inverters like the H5 inverter [14] and its derivatives use the DC-bypass technique that uses galvanic isolation without a common-mode voltage clamping approach; to prevent leakage current from flowing between the grid and the photovoltaic cell. As shown in Figure 3(b), H5 is a full-bridge inverter with four power switches $S_{1}-S_{4}$ and a switch $S_{5}$ connecting the photovoltaic cell to the full-bridge to achieve DCBypass. The gating signals are applied to power switches in such a way that switch $\mathrm{S}_{5}$ disconnects the photovoltaic cell from the inverter and thus from the grid during the freewheeling mode. To reduce leakage current, the highly efficient reliable inverter concept (Heric) and its derivatives use an AC-bypass technique which also comes under galvanic isolation without a common-mode voltage clamping approach. Heric has a full-bridge with four switches $S_{1}-S_{4}$ similar to the conventional full-bridge inverter. As mentioned in [15], additional switches $S_{5}$ and $S_{6}$ are added at the inverter output. The freewheeling current flows through these two switches in AC-bypass, preventing current from reaching the photovoltaic cell and thus disconnecting the photovoltaic cell from the grid. This inverter is more efficient than the H5 inverter because there are no additional switches in the active mode current path. The galvanic isolation with a common-mode voltage clamping approach is used in [16]. In this method, switches are connected in such a way that during freewheeling mode common-mode voltage is always equal to neutral point voltage. Hence the galvanic isolation can be acquired either on the AC side or the DC side of full-bridge or by using neutral point clamped topology by incorporating extra switches. Since a lower number of switches are present in the conduction path AC bypassing offers high efficiency than the DC bypass technique. In the AC bypass technique, high-frequency ripples may be present in the inverter due to the formation of a resonance circuit between the junction capacitance and the filter components. On the other hand, the neutral point clamping technique helps in keeping the common mode voltage constant that intern helps in keeping the leakage current as less as possible, but it requires spilt capacitors that must be balanced to gain the advantage of this approach.

Recently, much of the work has been focused on common ground technology. In common ground as name indicates, the PV ground and the grid grounds are connected together. As the two grounds are connected directly the common mode voltage becomes zero hence common mode leakage current as well. The author has proposed an inverter topology named as Type-I, Type-II and Type-III in [17]. Along with zero leakage current the main advantage of these topologies are in Type-I only two switches are active in power on mode while in Type-II only one switch. In Type-III author proposes a means of using a full bridge inverter in common ground configuration. Further another common ground topology that uses switched capacitor and virtual DC-link technique was presented in [18] with which it was possible to boost the voltage to two times without any extra inductors. The same author has proposed another similar topology in [19]. The difference in this topology is the number of devices used are lesser than used in the topology presented in [18]. Hence the cost of the inverter is expected to reduce along with all aforementioned advantages. An eight switch- five level inverter is proposed in [20] the advantage of the topology is that with only few number of switches it was able to achieve five levels and also the maximum number of switches coming in conduction path are limited to three. Hence this topology yields more efficiency. Due to the increase in levels the overall stress on the power devices is decreased and the power quality is also improved. Similar to this another multilevel inverter is proposed in [21] which carries the same benefits of eight switch five level inverter. A five-level inverter that employs series parallel switching conversion along with common ground technique is presented in [22]. Due to common grounding the leakage current is reduced and also it has reduced harmonics. Another similar type of five-level inverter with series parallel switching conversion and common ground technique is proposed in [23]. The main advantage of the inverter is, with only one stage it was able to output five-levels and also enhanced the output voltage. Common ground is a leading technique in the present year even though it has some limitations such as the requirement of large capacitor and the requirement of controlling the flow of inrush current in to this large capacitor which may damage the entire unit [24].

To take an advantage of all the isolation technique a hybrid topology which is a fusion of different inverter topologies can be used [25]. They are expected to yield good performance compared to using a single approach. Extensive work is already available in the literature that suggests the integration of neutral point clamping with the AC decoupling technique [26]-[28]. However, there is little research on the 
integration of all DC bypass with neutral point clamping, which may result in greater performance. In this paper, an effort is put in proposing one such hybrid technique for reducing the leakage current and the performance of the inverter is analyzed at the end.

The remainder of this paper is organized as follows: Section 2 includes a discussion on the proposed topology. Simulation results and comparison of the inverters are examined in section 3. Section 4 provides concluding remarks and future scope for the proposed hybrid method.

\section{PROPOSED TOPOLOGY}

As mentioned earlier to take an advantage of different approaches of leakage current reduction methods, a topology is proposed in this paper that includes a combination of DC bypassing and neutral point clamping. Figure 3(a) shows a conventional full-bridge inverter consisting of four switches $\mathrm{S}_{1}-\mathrm{S}_{4}$. In full bridge, each switch is operated with its dedicated driver circuit for applying sin pulse width modulated signal. The number of levels at the output of the inverter plays a significant role while designing a low pass filter for removing switching frequency components at the output of an inverter. The filter inductor size and hence the cost of filtering reduces with an increase in levels.

The conventional bipolar sine pulse width modulation (BSPWM) provides two levels, while unipolar and hybrid techniques provide three levels at the output. Hence from the filter design point of view, unipolar sine pulse width modulation (USPWM) and hybrid sine pulse width modulation (HSPWM) techniques are suitable. Also, the efficiency of both USPWM and HSPWM is better compared to BSPWM. The common-mode characteristics of the full-bridge inverter are always good in BSPWM mode, yet due to the advantages offered by USPWM and HSPWM, it's better to select any one of these two control signals for operating a full-bridge inverter. Among USPWM and HSPWM the latter gives good common mode performance. Hence, in the proposed topology HSPWM technique is used to control the power switches. To compare the results at every step, the full-bridge inverter is also simulated with the HSPWM technique.

Two diodes $D_{1}$ and $D_{2}$ are connected back-to-back in full bridge inverter as shown in Figure 3(c) to establish neutral point clamping. These diodes even though don't provide isolation, helps in clamping the output of the inverter to the neutral point during the freewheeling mode. For inclusion of DC bypass, a wellknown H5 topology is selected that has an extra switch $S_{5}$ at PV positive side or negative side. As DC bypassing at the negative side gives the best results in the proposed topology the switch is connected between PV negative and full-bridge inverter with HSPWM is used as shown in Figure 3(b). The switch $\mathrm{S}_{5}$ is active during inverter powering mode and is switched off during both negative and positive freewheeling mode. To form a hybrid model $\mathrm{H} 5$ inverter is integrated with the neutral point clamping network as suggested in Figure 3(c). Hence the complete circuit of the proposed Hybrid bypass topology is as shown in Figure 3(d).

In the structure of the topology, it can be noted that the diodes $\mathrm{D}_{1}$ and $\mathrm{D}_{2}$ make sure that the leakage current doesn't reach PV ground and under the non-ideal condition where the junction capacitances of the switches form a resonance along with the filter circuit the DC bypass switch keeps the PV module in isolation from the inverter. Hence, most of the leakage current flows through diodes $\mathrm{D}_{1}$ or $\mathrm{D}_{2}$ and finally reaches the neutral clamped point which considerably reduces the overall leakage current in the inverter. The same method can be applied for optimized H5 inverter presented in [29]. As shown in Figure 3(e). For better performance an IGBT without body diode as switch S7 is used. The pwm signal applied to it is complement of the power switch $\mathrm{S}_{5}$. Another DC-bypass inverter known as H6 inverter proposed in [30] is considered to check the feasibility of the proposed method. Figure 3(f) shows integration of H6 inverter with proposed clamping network. The PWM pulse for switch $S_{6}$ is same as switch $S_{5}$. All the three proposed inverter provides similar common mode and differential mode characteristics. But the resultant leakage current and common mode voltage is considerably reduced compared to their basic version. Among all the three inverters, number of power devices required are less in proposed H5-NPC. Hence only the topology H5-NPC is considered for further analysis. The inverter operates in four modes as explained;

\subsection{Mode-I}

Mode-I is a positive powering mode in this positive current flow through the load/AC gridconnected at the output of an inverter. The gating signals applied to the proposed inverter is as shown in Figure $3(\mathrm{~g})$. In this mode $S_{1}, S_{5}$ are operating at switching frequency while $S_{4}$ is operated at grid frequency. Both $S_{2}$ and $S_{3}$ are turned OFF. The flow of current direction in mode-I is as shown in Figure 4(a). The line voltage $V_{A N}$ is at $V_{P V}$ and $V_{B N}$ is zero volts. The calculation of common-mode voltage $V_{c m}$ and differentialmode voltage $V_{A B}$ can be done using (1) and (2). Hence, for mode-I $V_{c m}$ and $V_{A B}$ are given by (3) and (4). It can be observed that even after clamping the output to $\mathrm{V}_{\mathrm{PV}} / 2$ the output voltage in Mode-I is same as the applied input voltage $\mathrm{V}_{\mathrm{PV}}$. While in conventional neutral point clamping the output voltage is half of the input voltage that affects the overall performance of the inverter. 


$$
\begin{aligned}
& V_{D M}=V_{A B}=V_{A N}-V_{B N} \\
& V_{C M}=\frac{V_{A N}+V_{B N}}{2} \\
& V_{D M}=V_{A B}=V_{A N}-V_{B N}=+V_{P V}-0=+V_{P V} \\
& V_{C M}=\frac{V_{A N}+V_{B N}}{2}=\frac{V_{P V}+0}{2}=\frac{V_{P V}}{2}
\end{aligned}
$$

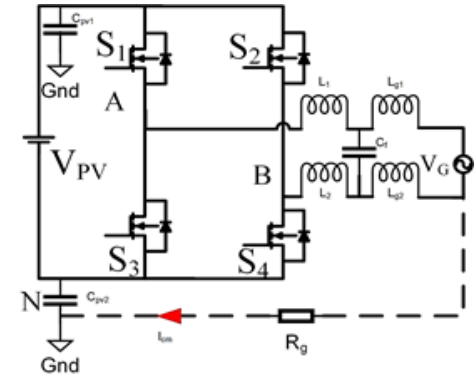

(a)

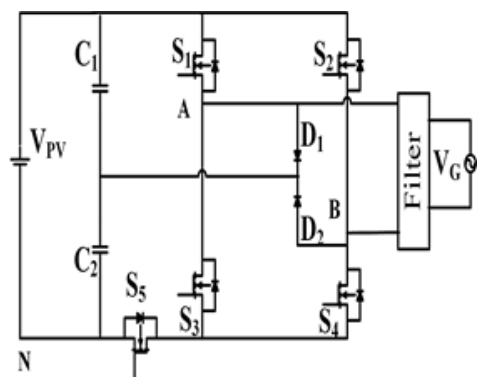

(d)

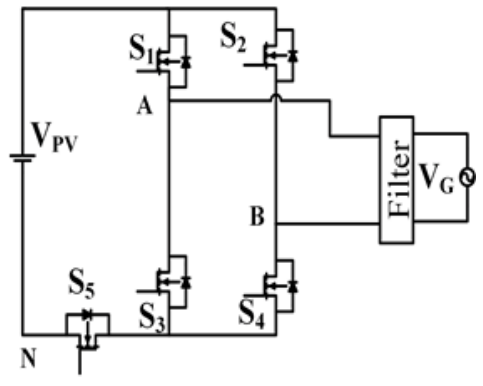

(b)

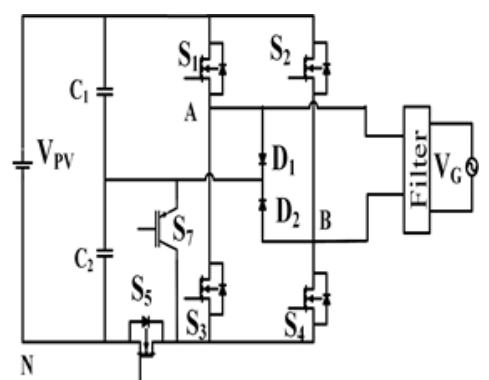

(e)

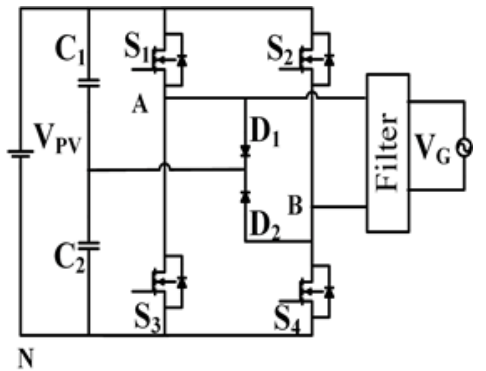

(c)

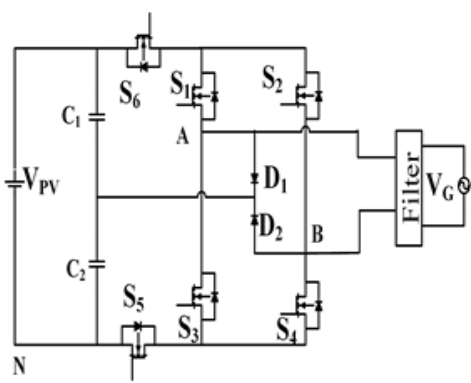

(f)

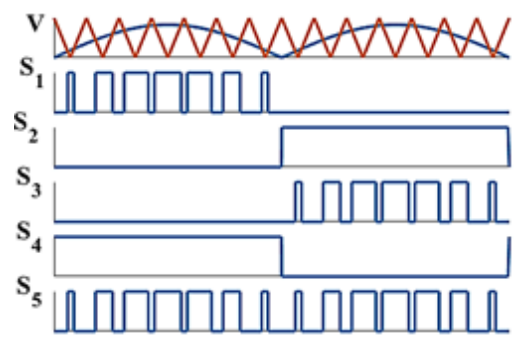

(g)

Figure 3. Grid-tied inverter using: (a) full bridge, (b) H5, (c) H4-NPC, (d) H5-NPC, (e) oH5-NPC, (f) H6-NPC, (g) HSPWM Pulses used for proposed topology

\subsection{Mode-II}

Mode-II is a positive freewheeling mode in which a positive freewheeling current flows. In this mode $S_{4}$ is ON while $S_{1}, S_{2}, S_{3}$ and $S_{5}$ are turned OFF. The flow of current direction in mode-II is as shown in Figure $4(\mathrm{~b})$. The line voltage $\mathrm{V}_{\mathrm{AN}}$ is at $\mathrm{V}_{\mathrm{PV}} / 2$ and $\mathrm{V}_{\mathrm{BN}}$ is $\mathrm{V}_{\mathrm{PV}} / 2$ volts. Hence, for mode-II $\mathrm{V}_{\mathrm{cm}}$ and $\mathrm{V}_{\mathrm{AB}}$ are given by (5) and (6). The common-mode voltage in mode-II is half of the input voltage.

$$
\begin{aligned}
& V_{D M}=V_{A B}=V_{A N}-V_{B N}=\frac{V_{P V}}{2}-\frac{V_{P V}}{2}=0 \\
& V_{C M}=\frac{V_{A N}+V_{B N}}{2}=\frac{\frac{V_{P V}}{2}+\frac{V_{P V}}{2}}{2}=\frac{V_{P V}}{2}
\end{aligned}
$$




\subsection{Mode-III}

Mode-III is a negative powering mode in this, negative current flow through load/AC gridconnected at the output of the inverter. In this mode $S_{3}, S_{5}$ are operating at switching frequency while $S_{2}$ is operated at grid frequency. Both $S_{1}$ and $S_{4}$ are turned OFF. The flow of current direction in mode-III is as shown in Figure $4(\mathrm{c})$. The line voltage $\mathrm{V}_{\mathrm{AN}}$ is at zero volts and $\mathrm{V}_{\mathrm{BN}}$ is $-\mathrm{V}_{\mathrm{PV}}$. Hence, for mode-III $\mathrm{V}_{\mathrm{cm}}$ and $\mathrm{V}_{\mathrm{AB}}$ are given by (7) and (8).

$$
\begin{aligned}
& V_{D M}=V_{A B}=V_{A N}-V_{B N}=0-V_{P V}=-V_{P V} \\
& V_{C M}=\frac{V_{A N}+V_{B N}}{2}=\frac{0+V_{P V}}{2}=\frac{V_{P V}}{2}
\end{aligned}
$$

\subsection{Mode-IV}

Mode-IV is a negative freewheeling mode, in this negative freewheeling current flows. The gating signals applied to the proposed inverter is as shown in Figure $3(\mathrm{~g})$. In this mode, $S_{2}$ is ON while $S_{1}, S_{3}, S_{4}$ and $S_{5}$ are turned OFF. The flow of current direction in mode-IV is as shown in Figure 4(d). The line voltage $\mathrm{V}_{\mathrm{AN}}$ is at $\mathrm{V}_{\mathrm{PV}} / 2$ and $\mathrm{V}_{\mathrm{BN}}$ is also $\mathrm{V}_{\mathrm{PV}} / 2$ volts. Hence, for mode-IV $\mathrm{V}_{\mathrm{cm}}$ and $\mathrm{V}_{\mathrm{AB}}$ are given by (9) and (10). The common-mode voltage in mode-IV is half of the input voltage.

$$
\begin{aligned}
& V_{D M}=V_{A B}=V_{A N}-V_{B N}=\frac{V_{P V}}{2}-\frac{V_{P V}}{2}=0 \\
& V_{C M}=\frac{V_{A N}+V_{B N}}{2}=\frac{\frac{V_{P V}}{2}+\frac{V_{P V}}{2}}{2}=\frac{V_{P V}}{2}
\end{aligned}
$$

The overall operation of the inverter shows that the magnitude of the common-mode voltage in all the modes is half of the input voltage.

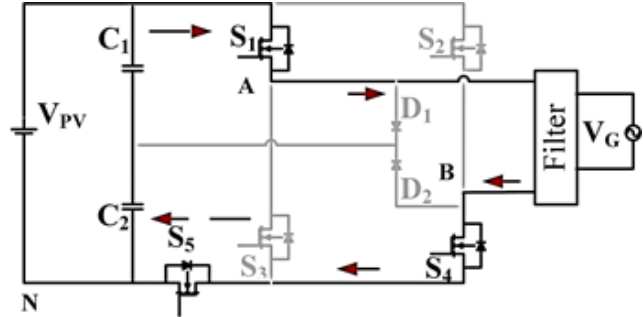

(a)

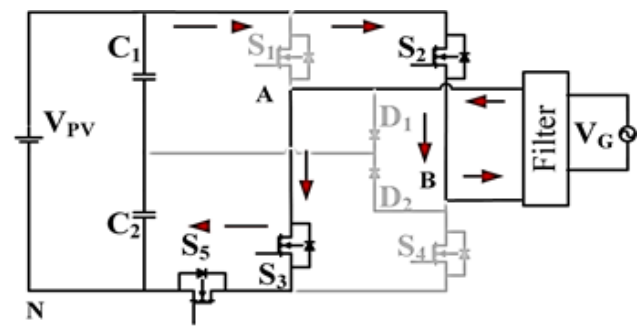

(c)

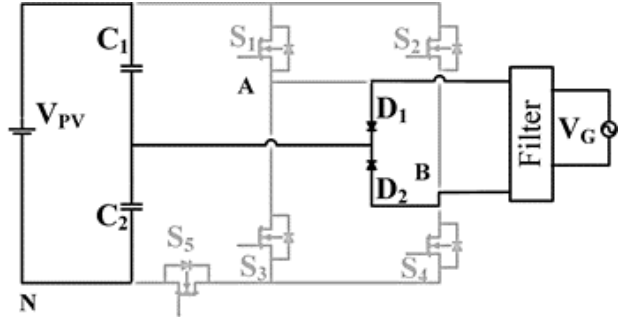

(b)

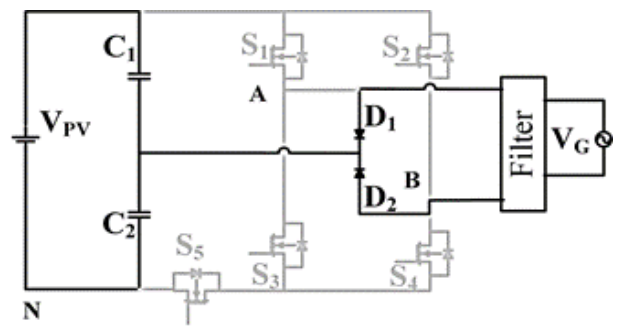

(d)

Figure 4. H5-NPC modes of operation: (a) Mode-I, (b) Mode-II, (c) Mode-III, (d) Mode-IV

\section{SIMULATION MODEL RESULTS AND COMPARISON}

To test and compare the results of the proposed hybrid bypass technique, all the circuits shown in Figure 3 are simulated using MATLAB Simulink. The simulation parameters used for testing the proposed topology are listed in Table 1. Second-order LCL filter with design techniques proposed in [31] is used to calculate the values of filter components. Achievement of grid synchronization for having control on active and reactive power is also essential to operate the inverter under grid optimal condition. The control system of the inverter must also include an MPPT control algorithm for generating a pulse for the DC-DC converter connected between the photovoltaic module and the inverter. In the presented work it is assumed that the DC- 
DC converter is controlled by the best MPPT algorithm and hence only the control algorithm required for grid synchronization is modelled. A well-known DQ-frame based active and reactive power current controller presented in [32] is used in the proposed inverter for generating the reference signal that is required to generate the HSPWM signal. The block level implementation of DQ-frame based current controller is as shown in Figure 5. The grid voltage, current and line \& phase voltages of the proposed inverter are as shown in Figures 6(a), and 6(b) respectively. The common-mode voltage and currents of full bridge, H5, H4-2D, and H5-NPC inverter are as shown in Figures 7(a) to 7(d). In these figures, it can be observed that with hybrid pulse width modulation, a single technique of galvanic isolation doesn't provide noticeable results. When it is integrated with neutral point clamping, leakage current has significantly dropped to $9 \mathrm{~mA}$ RMS and $88 \mathrm{~mA} \mathrm{P-P}$. Table 2 shows the comparison of the proposed inverters with literature concerning the number of power devices used, leakage current and total harmonic distortion. The listed results are obtained after simulating the referred topologies in the same model used to test the proposed topology. It can be noted from the comparison that the proposed inverter uses minimum number of power devices and gives leakage current within the acceptable limits of German DIN VDE 0126-1-1 i.e. $30 \mathrm{~mA}$ RMS [33], [34] and also has the harmonic distortion content within the limit stated by IEEE Std 519-2014 [35]. It is observed that oH5NPC and H6-NPC inverter leakage current is lesser than its traditional versions and total harmonic distortion is lesser than H5-NPC topology. Figures 7(e) and 7(f) shows voltage stress on the power devices.

Table 1. Simulation parameters

\begin{tabular}{ccc}
\hline \multicolumn{3}{c}{ Parameters } \\
\hline Power rating & $\mathrm{P}_{\mathrm{i}}$ & $1 \mathrm{~kW}$ \\
Grid voltage & $\mathrm{V}_{\mathrm{G}}$ & $230 \mathrm{~V}$ \\
Grid Frequency & $\mathrm{f}_{\mathrm{g}}$ & $50 \mathrm{~Hz}$ \\
Switching frequency & $\mathrm{f}_{\mathrm{sw}}$ & $20 \mathrm{kHz}$ \\
PV Voltage & $\mathrm{V}_{\mathrm{PV}}$ & $400 \mathrm{~V}$ \\
Split capacitor & $\mathrm{C}_{1}, \mathrm{C}_{2}$ & $560 \mu \mathrm{f}$ \\
Filter inductors & $\mathrm{L}_{1}, \mathrm{~L}_{2}, \mathrm{~L}_{\mathrm{g} 1}, \mathrm{~L}_{\mathrm{g} 2}$ & $4 \mathrm{mH}$ \\
Filter Capacitor & $\mathrm{C}_{\mathrm{f}}$ & $1 \mu \mathrm{f}$ \\
Parasitic Capacitor & $\mathrm{C}_{\mathrm{PV} 1}, \mathrm{C}_{\mathrm{PV} 2}$ & $0.1 \mu \mathrm{f}$ \\
\hline
\end{tabular}

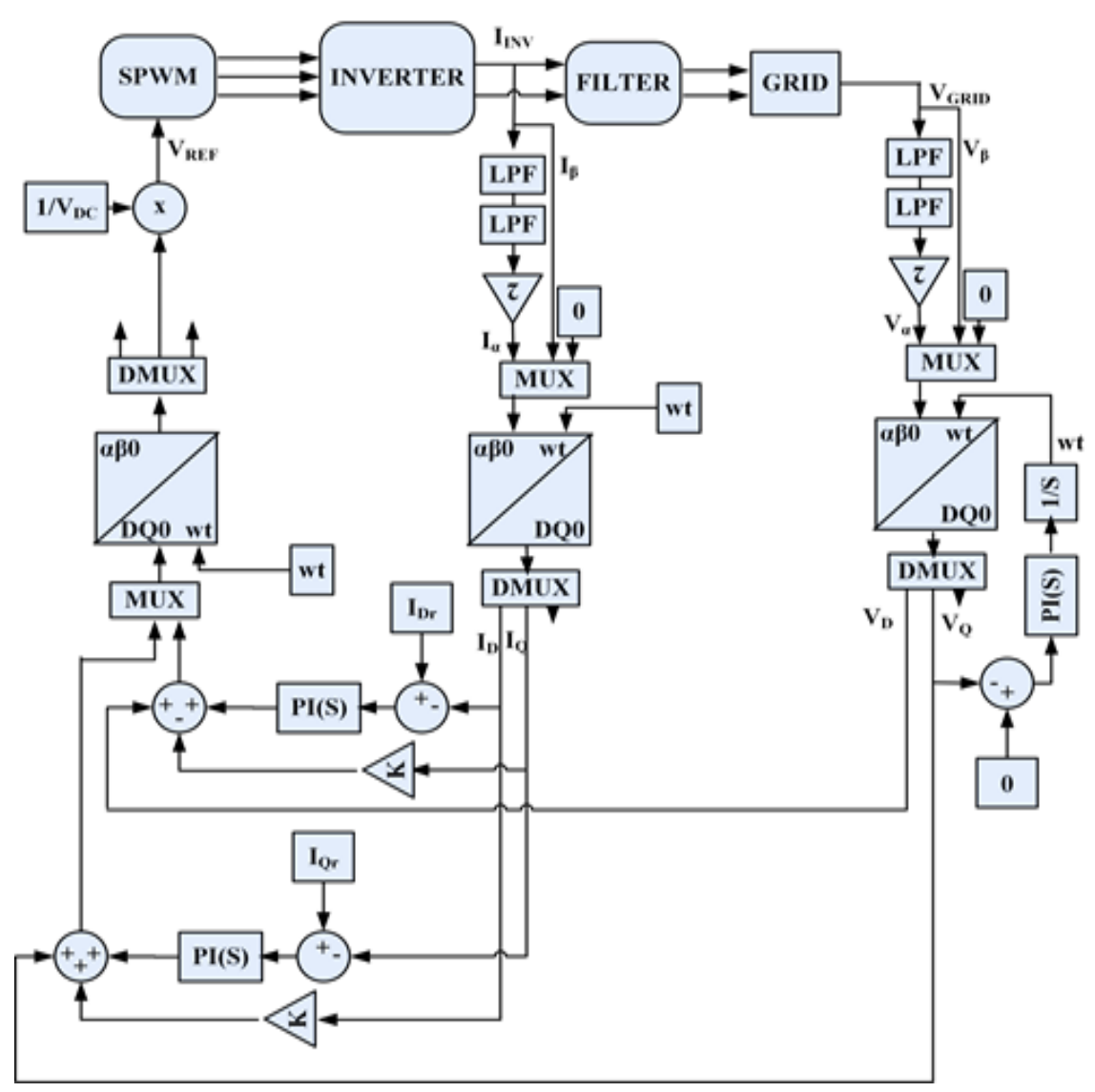

Figure 5. DQ frame based current controller 

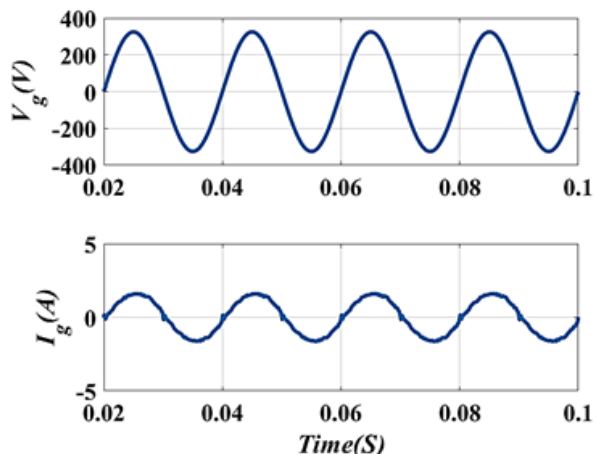

(a)
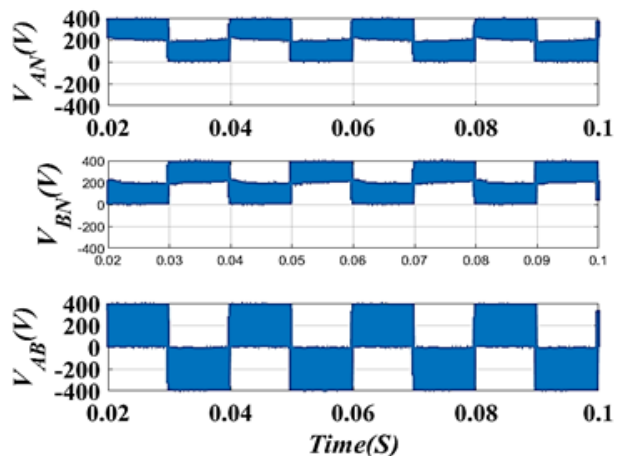

(b)

Figure 6. The grid voltage, current and line \& phase voltages, (a) grid voltage, (b) grid current H5-NPC
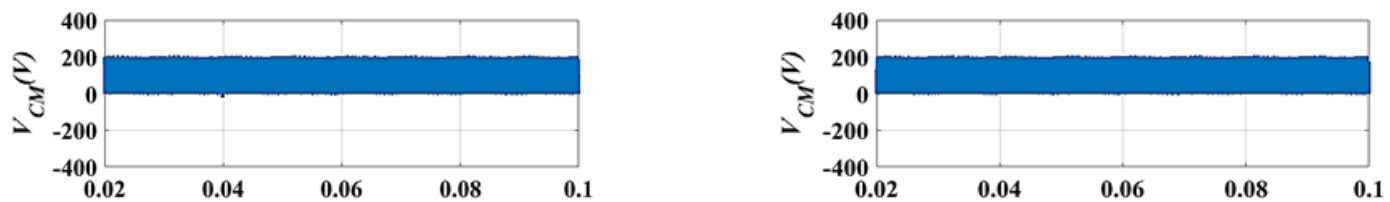

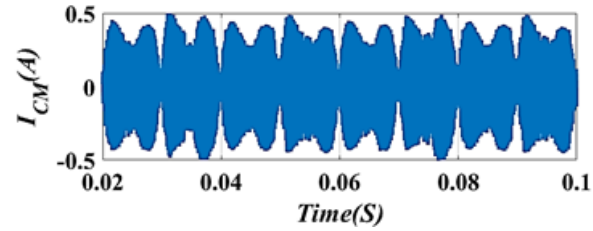

(a)
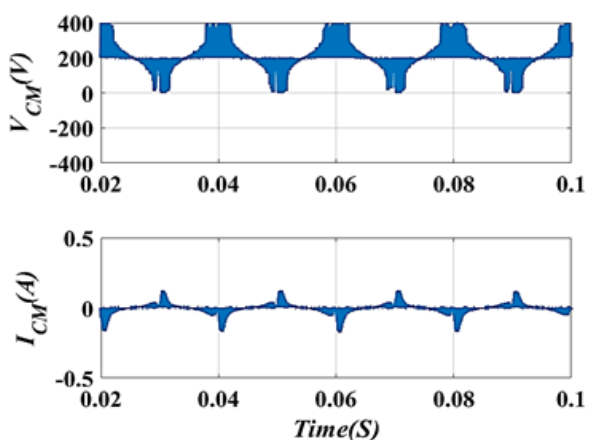

(c)
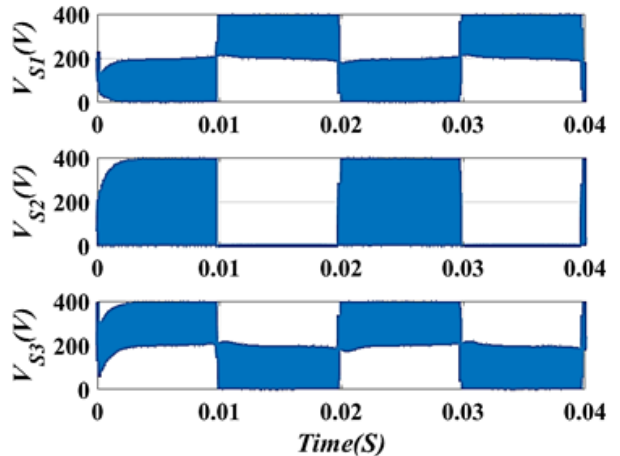

(e)

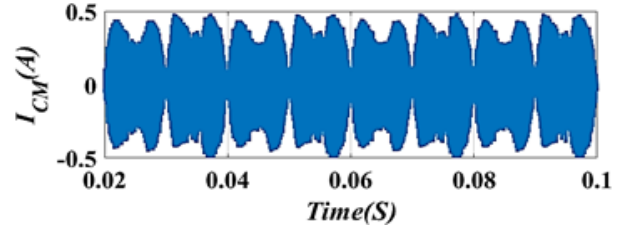

(b)
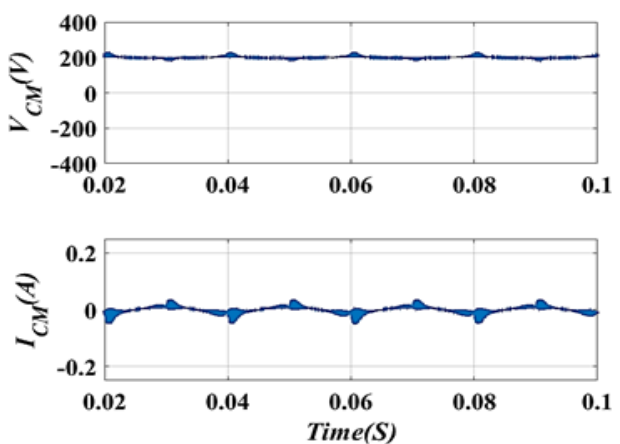

(d)
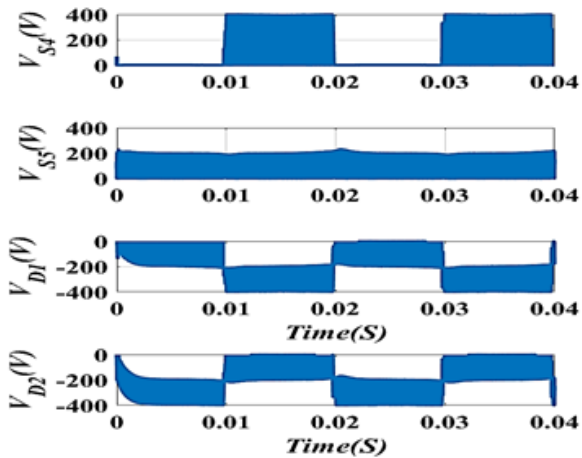

(f)

Figure 7. Common mode voltage and leakage current of (a) full bridge, (b) H4-NPC, (c) H5, (d) H5-NPC, (e) and (f) voltage stress on power devices in H5-NPC 
Table 2. Comparison

\begin{tabular}{cccccc}
\hline \multirow{2}{*}{ Topology } & \multirow{2}{*}{ S } & D & Current THD $(\%)$ & \multicolumn{2}{c}{ Leakage Current } \\
rms (mA) & P-P (mA) \\
\hline H5 [18] & 5 & - & NA & 15.3 & 282 \\
oH5 [29] & 6 & - & NA & 14.5 & 281 \\
H6 [30] & 6 & - & NA & 15.5 & 294 \\
FBDC [36] & 6 & 2 & NA & 7.5 & 50 \\
Heric [19] & 6 & - & NA & 14.7 & 274 \\
PNNPC [37] & 8 & - & 1.6 & 8.19 & 68 \\
H5-NPC & 5 & 2 & 2 & 9 & 88 \\
oH5-NPC & 6 & 2 & 1.59 & 9.1 & 92 \\
H6-NPC & 6 & 2 & 1.62 & 9.1 & 94 \\
\hline
\end{tabular}

\section{CONCLUSION}

In this paper, an effort is made to display the concept of a hybrid bypassing technique to improve the performance of the inverter. Even though in literature there are many hybrid models available the efforts made in using both DC bypass and neutral point clamping are lesser compared to integrating AC bypass and neutral clamping. In this paper to support the concept proposed a new single-phase grid-tied inverters with a hybrid bypass technique that integrates DC bypass and neutral point clamping is presented. The performance of the proposed topology is compared with literature and it is found that the presented concept yields a leakage current of about $9 \mathrm{~mA} \mathrm{RMS}$, total harmonic distortion of about $2 \%$. As the number of devices used in the inverter is considerably less compared to other topologies referred to, the proposed inverter is expected to exhibit good efficiency. The leakage current and common-mode voltage of the inverter has high-frequency ripples in the proposed inverter. Hence improvement in terms of removing these high-frequency ripples can be carried out in the near future. A pulse width modulation technique can be revamped to see if these inverters can be operated at twice the switching frequency.

\section{REFERENCES}

[1] L. Hassaine, E. OLias, J. Quintero, and V. Salas, "Overview of power inverter topologies and control structures for grid connected photovoltaic systems," Renewable and Sustainable Energy Reviews, vol. 30, pp. 796-807, 2014, doi: 10.1016/j.rser.2013.11.005.

[2] O. Ellabban, H. Abu-Rub, and F. Blaabjerg, "Renewable energy resources: Current status, future prospects and their enabling technology," Renewable and Sustainable Energy Reviews, vol. 39, pp. 748-764, 2014, doi: 10.1016/j.rser.2014.07.113.

[3] K. Zeb et al., "A comprehensive review on inverter topologies and control strategies for grid connected photovoltaic system," Renewable and Sustainable Energy Reviews, vol. 94, pp. 1120-1141, 2018, doi: 10.1016/j.rser.2018.06.053.

[4] B. I. Yassine and A. Boumediene, "Renewable energies evaluation and linking to smart grid," Int. J. of Power Electronics and Drive System (IJPEDS), vol. 11, no. 1, pp. 107-118, 2020, doi: 10.11591/ijpeds.v11.i1.pp107-118.

[5] J. Kumar, N. R. Parhyar, M. K. Panjwani, and D. Khan, "Design and performance analysis of PV grid-tied system with energy storage system," International Journal of Electrical and Computer Engineering (IJECE), vol. 11, no. 2, pp. 1077-1085, 2021, doi: 10.11591/ijece.v11i2.pp1077-1085.

[6] H. Ritchie and M. Roser, "Renewable Energy," Our World in Data, 2020. [Online]. Available: https://ourworldindata.org/renewable-energy

[7] P. Singh. "Global Solar Capacity Set to Exceed $150 \mathrm{GW}$ in 2021." Saur Energy International. www.saurenergy.com. 2021. https://www.saurenergy.com/solar-energy-news/global-solar-capacity-set-to-exceed-150-gw-in-2021

[8] Z. Rasin, M. F. Rahman, M. Azri, M. H. N. Talib, and A. Jidin, "Design and development of grid-connected quasi-Z-source PV inverter," International Journal of Power Electronics and Drive System (IJPEDS), vol. 9, no. 4, pp. 1989-2005, 2018, doi:10.11591/ijpeds.v9.i4.pp1989-2005.

[9] L. Hassaine and M. R. Bengourina, "Design and digital implementation of power control strategy for grid connected photovoltaic inverter," International Journal of Power Electronics and Drive System (IJPEDS), vol. 10, no. 3, pp. 1564-1574, 2019, doi:10.11591/ijpeds.v10.i3.1564-1574.

[10] D. Sera, L. Mathe, and F. Blaabjerg, "Distributed control of PV strings with module integrated converters in presence of a central MPPT," IEEE Energy Conversion Congress and Exposition (ECCE), 2014, pp. 1-8, doi: 10.1109/ECCE.2014.6953368.

[11] M. A. Eltawil and Z. Zhao, "Grid-connected photovoltaic power systems: technical and potential problems-a review," Renewable and Sustainable Energy Reviews, vol. 14, no. 1, pp. 112-129, 2010, doi: 10.1016/j.rser.2009.07.015.

[12] Suroso and H. Siswantoro, "A performance comparison of transformer-less grid tied PV system using diode clamped and neutral point shorted inverters," International Journal of Power Electronics and Drive System (IJPEDS), vol. 11, no. 2, pp. 702-710, 2020, doi: 10.11591/ijpeds.v11.i2.pp702-710.

[13] L. Ma, F. Tang, F. Zhou, X. Jin, and Y. Tong, "Leakage current analysis of a single-phase transformer-less PV inverter connected to the grid," IEEE International Conference on Sustainable Energy Technologies, 2008, pp. 285-289, doi: 10.1109/ICSET.2008.4747018

[14] M. Victor, F. Greizer, S. Bremicker, and U. Hibler, "Method of converting a direct current voltage from a source of direct current voltage, more specifically from a photovoltaic source of direct current voltage, into a alternating current voltage," US 7.411.802 B2, 2008.

[15] S. Heribert, S. Christoph, and K. Jurgen, "Inverter for transforming a DC voltage into an AC current or an AC voltage," EP1369985A2, 2011.

[16] Y. Wang, W. W. Shi, N. Xie, and C. M. Wang, "Diode-free t-type three-level neutral-point-clamped inverter for low-voltage renewable energy system," IEEE Transactions on Industrial Electronics, vol. 61, no. 11, pp. 6168-6174, Nov. 2014, doi: 10.1109/TIE.2014.2311407. 
[17] Y. P. Siwakoti and F. Blaabjerg, "Common-ground-type transformerless inverters for single-phase solar photovoltaic systems," IEEE Trans. on Indust. Elec., vol. 65, no. 3, pp. 2100-2111, 2018, doi: 10.1109/TIE.2017.2740821.

[18] N. Vosoughi, S. H. Hosseini, and M. Sabahi. "Single-phase common-grounded transformerless grid-tied inverter for PV application," IET Power Electronics, vol. 13, no. 1, pp. 157-167, 2020, doi: 10.1049/iet-pel.2019.0364.

[19] N. V. Kurdkandi, M. G. Marangalu, Y. Naderi, S. H. Hosseini and M. Sabahi, "Single-phase inverter with common grounded feature and connected into grid," 28th Iranian Conference on Electrical Engineering (ICEE), 2020, pp. 1-5, doi: 10.1109/ICEE50131.2020.9260847.

[20] S. Kumar, A. K. Verma, Sandeep N., U. R. Yaragatti, and H. R. Pota, "An eight-switch five-level inverter with zero leakage current," IET Power Electronics, vol. 14, no. 2, pp. 590-601, 2021, doi: 10.1049/pel2.12041.

[21] S. Kumar, A. K. Verma, Sandeep N., U. R. Yaragatti, and H. R. Pota, "Multilevel common-ground inverter with voltage boosting for PV applications," IET Power Electron, vol. 14. pp. 901-911, 2021, doi: 10.1049/pel2.12073.

[22] N. Vosoughi, S. H. Hosseini, and M. Sabahi, "A new transformer-less five-level grid-tied inverter for photovoltaic applications," IEEE Transactions on Energy Conversion, vol. 35, no. 1, pp. 106-118, 2020, doi: 10.1109/TEC.2019.2940539.

[23] R. Barzegarkhoo, Y. P. Siwakoti, N. Vosoughi, and F. Blaabjerg, "Six-switch step-up common-grounded five-level inverter with switched-capacitor cell for transformerless grid-tied PV applications," IEEE Transactions on Industrial Electronics, vol. 68, no. 2, pp. 1374-1387, 2021, doi: 10.1109/TIE.2020.2967674.

[24] S. U. Hasan, B. Shaffer, H. A. Hassan, M. J. Scott, Y. Siwakoti, and G. E. Town, "Common-ground transformerless inverter for solar photovoltaic module," in 2018 IEEE Applied Power Electronics Conference and Exposition (APEC), San Antonio, TX, 2018, pp. 167-172, doi: 10.1109/APEC.2018.8341004.

[25] S. Kumar and M. S. Kumar, "Asymmetric hybrid multilevel inverter with reduced harmonic using hybrid modulation technique," International Journal of Power Electronics and Drive System (IJPEDS), vol. 11, no. 2, pp. 605-610, 2020, doi: 10.11591/ijpeds.v11.i2.pp605-610.

[26] S. Hu, C. Li, W. Li, X. He, and F. Cao, "Enhanced HERIC based transformerless inverter with hybrid clamping cell for leakage current elimination," in IEEE Energy Conversion Congress and Exposition (ECCE), Montreal, 2015, pp. 5337-5341, doi: 10.1109/ECCE.2015.7310410.

[27] G. I. Orfanoudakis, S. M. Sharkh, E. Koutroulis, and M. A. Yuratich, "Single-phase transformerless PV inverter topology with AC bypass and mid-DC-link voltage clamping," in 19th European Conf. on Power Electronics and Applications, 2017, pp. P.1-P.10, doi: 10.23919/EPE17ECCEEurope.2017.8098973.

[28] W. Li, Y. Gu, H. Luo, W. Cui, X. He, and C. Xia, "Topology review and derivation methodology of single-phase transformerless photovoltaic inverters for leakage current suppression," IEEE Transactions on Industrial Electronics, vol. 62, no. 7, pp. 4537-4551, Jul. 2015, doi: 10.1109/TIE.2015.2399278.

[29] H. Xiao, S. Xie, Y. Chen, and R. Huang, “An optimized transformerless photovoltaic grid-connected inverter," IEEE Trans. Ind. Electron, vol. 58, no. 5, pp. 1887-1895, 2011, doi: 10.1109/TIE.2010.2054056.

[30] R. Gonzalez, J. Lopez, P. Sanchis, E. Gubia, A. Ursua, and L. Marroyo, "High-efficiency transformerless single-phase photovoltaic inverter," 12th Int. Power Electronics and Motion Control Conference, 2006, pp. 1895-1900, doi: 10.1109/EPEPEMC.2006.4778682.

[31] J. Sedo and S. Kascak, "Design of output LCL filter and control of single-phase inverter for grid-connected system," Electr. Eng., vol. 99, no. 4, pp. 1217-1232, 2017. doi: 10.1007/s00202-017-0617-0.

[32] S. Zhou, J. Liu, L. Zhou, and Y. Zhang, "DQ current control of voltage source converters with a decoupling method based on preprocessed reference current feed-forward," in IEEE Transactions on Power Electronics, vol. 32, no. 11, pp. 8904-8921, Nov. 2017, doi: 10.1109/TPEL.2017.2651139

[33] Standard DIN VDE 0126-1-1, "Automatic disconnection device between a generator and the public low-voltage grid," Feb. 2006.

[34] A. K. Gupta, H. Agrawal, and V. Agarwal, "A novel three-phase transformerless h-8 topology with reduced leakage current for grid-tied solar pv applications," in IEEE Transactions on Industry Applications, vol. 55, no. 2, pp. 1765-1774, Mar.-Apr. 2019. doi: 10.1109/TIA.2018.2883372

[35] IEEE Recommended Practice and Requirements for Harmonic Control in Electric Power Systems, in IEEE Std 519-2014 (Revision of IEEE Std 519-1992), pp. 1-29, Jun. 2014.

[36] R. Gonzalez, J. Lopez, P. Sanchis, and L. Marroyo, "Transformerless inverter for single-phase photovoltaic systems," IEEE Trans. on Power Elect., vol. 22, no. 2, pp. 693-697, Mar. 2007, doi: 10.1109/TPEL.2007.892120.

[37] L. Zhang, K. Sun, L. Feng, H. Wu, and Y. Xing, "A family of neutral point clamped full-bridge topologies for transformerless photovoltaic grid-tied inverters," IEEE Trans. Power Electron., vol. 28, no. 2, pp. 730-739, 2013. doi: 10.1109/TPEL.2012.2205406. 